\section{A case of dyspnoea and visible neck pulsations}

\section{CLINICAL INTRODUCTION}

A 48-year-old male patient with a history of New York Heart Association (NYHA) Class II dyspnoea for the last 2 years presented with acute onset breathlessness associated with orthopnoea and palpitations. The symptom aggravation was abrupt with simultaneous occurrence of both dyspnoea and palpitations. After medical stabilisation, the neck pulsations were as shown in online supplementary video 1 .

\section{QUESTION}

What is the most likely cardiac condition?

A. Aortic regurgitation

B. Congestive cardiac failure

C. Tricuspid regurgitation

D. Ventricular tachycardia 


\section{ANSWER: A}

The major clue here is to find out whether it is an arterial pulsation or a venous pulsation. Typically, an elevated jugular venous pulse (JVP) will be equally or more prominent at the root of the neck and will show an upper level. The descents will be more prominent than the outward pulsations. ${ }^{1}$ On the contrary, arterial neck pulsations will be most prominent at the mid-neck level with little or no appreciable pulsation at the root of the neck. Moreover, the pulsations will not show an upper level, and the outward pulsations will be better appreciable than the descents. Keeping this in mind, the neck pulsations in the video fit into an arterial one rather than venous considering its maximum prominence at the mid-neck level, no discernible upper level and little pulsations at the root of the neck. Bisferiens pulse is an arterial pulse with double peaking in systole usually seen in combined severe aortic regurgitation (AR) with mild aortic stenosis, but has also been described in isolated severe AR and hypertrophic obstructive cardiomyopathy. It is usually described as a palpatory finding, but to be able to see the bisferiens character is rare and not been reported in literature. ${ }^{2}$

Next thing to be assessed is its periodicity. The pulsations appear to come in regular pairs. If it were to be venous pulsations, such regular periodicity could not have been explained by any of the given options. Congestive cardiac failure will only show an elevated mean JVP with visible a and $\mathrm{v}$ waves with prominent engorgement of the root of neck. Also, only the a waves in the JVP will have a sharp flicking character, while the $\mathrm{v}$ waves will be a surging wave as opposed to the waves seen in online supplementary video 1 , where both the waves are sharp and flicking. ${ }^{3}$ Ventricular tachycardia in a case of dilated cardiomyopathy will have irregular cannon waves if there is no ventriculoatrial conduction. Pulmonary hypertension with severe TR will have surging $\mathrm{v}$ waves on JVP along with the engorgement visible at the root of the neck and no periodicity of pairs as noted in this video.

Panakkal Jose Benny, Gopalan Nair Rajesh, Chakkanalil Govindan Sajeev Department of Cardiology, Government Medical College, Kozhikode, Kerala, India

Correspondence to Dr Panakkal Jose Benny, Senior Resident, Department of Cardiology, Government Medical College, Kozhikode 673008, Kerala, India; bennyjose666@gmail.com

Twitter Follow Benny Panakkal at @bennyjose666

Contributors All authors satisfy the authorship criteria.

Competing interests None declared.

Patient consent Obtained.

Provenance and peer review Not commissioned; externally peer reviewed.

- Additional material is published online only. To view, please visit the journal online (http://dx.doi.org/10.1136/heartjnl-2015-308831).

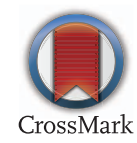

To cite Benny PJ, Rajesh GN, Sajeev CG. Heart 2016;102:e1.

Received 10 October 2015

Revised 16 November 2015

Accepted 27 November 2015

Published Online First 13 January 2016

Heart 2016;102:e1. doi:10.1136/heartjnl-2015-308831

\section{REFERENCES}

1 Perloff JK. The jugular venous pulse and third heart sound in patients with heart failure. N Engl J Med 2001;345:612-14.

2 Fleming PR. The mechanism of the pulsus bisferiens. Br Heart J 1957;19: 519-24.

3 Applefeld MM. The jugular venous pressure and pulse contour. In: Walker HK, Hall WD, Hurst JW, eds. Clinical methods: the history, physical, and laboratory examinations. 3rd edn. Boston: Butterworths, 1990. Chapter 19, pp 107-111. 